\title{
Arsenate resistance in the unicellular marine diazotroph Crocosphaera watsonii
}

\section{Sonya T. Dyhrman* and Sheean T. Haley}

Department of Biology, Woods Hole Oceanographic Institution, Woods Hole, MA, USA

\section{Edited by:}

George S. Bullerjahn, Bowling Green

State University, USA

\section{Reviewed by:}

Matthew Church, University of Hawail at Manoa, USA

Lisa Moore, University of Southern

Maine, USA

Eric A. Webb, University of Southern

California, USA

\section{*Correspondence:}

Sonya T. Dyhrman, Department of Biology MS\#33, Woods Hole

Oceanographic Institution, Woods

Hole, MA 02543, USA.

e-mail:sdyhrman@whoi.edu

\begin{abstract}
The toxic arsenate ion can behave as a phosphate analog, and this can result in arsenate toxicity especially in areas with elevated arsenate to phosphate ratios like the surface waters of the ocean gyres. In these systems, cellular arsenate resistance strategies would allow phytoplankton to ameliorate the effects of arsenate transport into the cell. Despite the potential coupling between arsenate and phosphate cycling in oligotrophic marine waters, relatively little is known about arsenate resistance in the nitrogen-fixing marine cyanobacteria that are key components of the microbial community in low nutrient systems. The unicellular diazotroph, Crocosphaera watsonii WH8501, was able to grow at reduced rates with arsenate additions up to $30 \mathrm{nM}$, and estimated arsenate to phosphate ratios of 6:1. The genome of strain WH8501 contains homologs for ars $A$, ars $H$, arsB, and ars $C$, allowing for the reduction of arsenate to arsenite and the pumping of arsenite out of the cell. The short-term addition of arsenate to the growth medium had no effect on nitrogen fixation. However, arsenate addition did result in the up-regulation of the ars $B$ gene with increasing arsenate concentrations, indicating the induction of the arsenate detoxification response. The ars $B$ gene was also up-regulated by phosphorus stress in concert with a gene encoding the high-affinity phosphate binding protein pstS. Both genes were down-regulated when phosphate was re-fed to phosphorus-stressed cells. A field survey of surface water from the low phosphate western North Atlantic detected expression of $C$. watsonii arsB, suggestive of the potential importance of arsenate resistance strategies in this and perhaps other systems.
\end{abstract}

Keywords: cyanobacteria, phosphorus, marine, arsenate, diazotroph, Crocosphaera

\section{INTRODUCTION}

Arsenic is prevalent in the marine environment, where it can occur as arsenite [As (III)] and arsenate [As (V)]. Both oxidation forms are toxic to the majority of living organisms, with arsenite interfering with enzyme function, and arsenate, the thermodynamically dominant form in most oxygenated surface waters (as $\mathrm{AsO}_{4}^{3-}$ ), behaving as a phosphate analog (Apte et al., 1986) and disrupting phosphate uptake and utilization (Wängberg and Blanck, 1990; Bleeker et al., 2003).

In the surface ocean, arsenic has relatively high concentrations and follows a nutrient-like profile, with less arsenic at the surface than at depth suggestive of biological uptake and transport (Andreae, 1979; Cutter and Cutter, 1995). Due to the potential competitive inhibition between arsenate and phosphate (Smedley and Kinniburgh, 2002; Manomita et al., 2004), arsenate resistance, or detoxification pathways may be particularly important in low phosphate systems like the ocean gyres, including the western North Atlantic where surface phosphate levels are typically around $5 \mathrm{nM}$ and can be sub-nanomolar (Wu et al., 2000; Lomas et al., 2010). Surface inorganic arsenic (arsenate and arsenite) concentrations in this region can be $>12 \mathrm{nM}$ (Cutter and Cutter, 1995) with an arsenic to phosphate ratio thus exceeding 2:1.

It has been proposed that under low phosphate conditions, microbial uptake of arsenate and its subsequent reduction to and excretion as arsenite is rapid (Andreae, 1979). There are relatively few studies of arsenic speciation in the ocean gyres, but of the studies that have been done, the speciation of dissolved arsenic (arsenite, arsenate, and methylated arsenic forms) was subtly controlled by the arsenate to phosphate ratio (Cutter and Cutter, 2006). The microbial detoxification products of arsenic including arsenite and methylated forms of arsenic have surface maxima, and in a study of profiles in the western Atlantic tracked closely with the chlorophylla profile (Cutter and Cutter, 1995). These detoxification products have a short (days-months) residence time and their presence suggests active microbial arsenic detoxification in the surface ocean. Although some arsenic accumulation can occur in microbes (Statham et al., 1987), arsenic distributions suggest that the uptake of arsenic by phytoplankton primarily results in cycling between chemical forms within the euphotic zone and that the flux of arsenic into the deep ocean by particle transport is relatively minor (Andreae, 1979; Sanders and Windom, 1980).

Because of the prevalence of arsenic in the environment and its toxicity, many microbes carry well-described pathways for arsenate detoxification or resistance. The most common arsenate resistance system (ars) involves an arsenate reductase (ArsC), an arsenite efflux pump (ArsB or ACR3), and a transcriptional repressor (ArsR; Rosen, 1999; Mukhopadhyay et al., 2002; Busenlehner et al., 2003; López-Maury et al., 2003). Some bacteria also 
possess other ars genes including ars $A$, an arsenite-stimulated ATPase that results in more efficient arsenite efflux through ArsB (Ordóñez et al., 2005; Silver and Phung, 2005). The presence of arsenate detoxification genes has been reported in a wide variety of picocyanobacteria (López-Maury et al., 2003; Scanlan et al., 2009). Furthermore, Prochlorococcus arsenate resistance genes are overrepresented in metagenome sequence from the surface North Atlantic with an elevated arsenate to phosphate ratio relative to the North Pacific (Coleman and Chisholm, 2010). This finding underscores the potential importance of arsenate detoxification, especially in the low phosphorus North Atlantic, yet arsenate resistance strategies have not been investigated in the unicellular marine nitrogen-fixing cyanobacteria.

In the oligotrophic oceans, nitrogen-fixing cyanobacteria are considered "keystone" species (Hewson et al., 2009a), because of their low relative abundance but significance to carbon and nitrogen fixation. Of these nitrogen-fixing cyanobacteria, unicellular diazotrophs are increasingly recognized as critically important to nitrogen cycling (Montoya et al., 2004), but are less well understood relative to larger filamentous nitrogen-fixing cyanobacteria like Trichodesmium. Phylogenetic analyses of the nitrogenaseencoding nifH sequences obtained from field surveys have shown that there are two distinct groups of the unicellular diazotrophs, one of which (group B) includes Crocosphaera watsonii WH8501 (Zehr et al., 2001; Falcón et al., 2002, 2004). C. watsonii is widely distributed through the surface waters of the tropical oceans (Church et al., 2005; Zehr et al., 2007), including low phosphate environments like the Sargasso Sea (Hewson et al., 2007). Recent work leveraging the whole genome sequence of $C$. watsonii WH8501 suggests that it has a robust capacity for scavenging phosphorus (e.g., presence of pstSCAB, a high-affinity phosphate transport system; Dyhrman and Haley, 2006), and as a diazotroph, it may drive down local phosphorus concentrations via nitrogen fixation. In these low phosphate scenarios there may be coupling between arsenate and phosphate cycling with the possible induction of arsenate detoxification or resistance strategies. Here we used a combination of genomic observations, physiological studies, and field analyses to examine arsenate resistance in C. watsonii.

\section{MATERIALS AND METHODS CULTURE CONDITIONS}

Axenic Crocosphaera watsonii WH8501, previously designated as Synechocystis sp. strain WH8501, was obtained from John B. Waterbury at Woods Hole Oceanographic Institution. Cultures were grown at $27.5^{\circ} \mathrm{C}$ using a $14: 10 \mathrm{~h}$ light dark cycle provided by cool white fluorescent bulbs with $\sim 65 \mu \mathrm{mol}$ quanta $\mathrm{m}^{-2} \mathrm{~s}^{-1}$. Unless otherwise noted phosphorus replete (referred to as $+\mathrm{P}$ or Replete) cultures were grown in $2 \mathrm{~L}$ SO medium (Waterbury et al., 1986), made with a $0.2 \mu \mathrm{m}$ filtered $75 \%$ Sargasso seawater base and $45 \mu \mathrm{M} \mathrm{K}_{2} \mathrm{HPO}_{4}$. Continued sterility was confirmed by testing for growth of contaminating organisms with a tryptone-fortified medium (Andersen et al., 1991). Growth was monitored by in vivo fluorescence on a Turner Designs TD-700 fluorometer.

\section{ARSENATE AND PHOSPHATE GROWTH EXPERIMENT}

Crocosphaera watsonii WH8501 was grown in triplicate on different concentrations of added arsenate and phosphate in SO medium made as above and amended with no added phosphate (NoP), $500 \mathrm{nM}$ phosphate (LowP), and $45 \mu \mathrm{M}$ phosphate (Replete). Sterile-filtered $(0.2 \mu \mathrm{m})$ arsenate was added as ACSgrade sodium arsenate, $\mathrm{Na}_{2} \mathrm{HAsO}_{4} \cdot 7 \mathrm{H}_{2} \mathrm{O}$ (Chem Service, West Chester, PA, USA) in appropriate quantities to yield the following final concentrations in the NoP treatments: $0,15,30,150$, 500,1000 , and $5000 \mathrm{nM}$. Arsenate was added to the LowP treatments to yield the following final concentrations: $0,500,1000$, and $5000 \mathrm{nM}$. No arsenate was added to the Replete cultures as a control. Cells used as the inoculum for all treatments were centrifuged initially for $10 \mathrm{~min}$ at $7000 \mathrm{rpm}$ and resuspended in medium without added phosphate to restrict carryover. Where no arsenate or phosphate was added to the cultures, As:P ratios were estimated based on literature values for ambient arsenate ( $12 \mathrm{nM}$; Cutter and Cutter, 1995) and phosphate concentrations (5 nM; Jakuba et al., 2008) for the region where the water was collected.

\section{ARSENATE ADDITION EXPERIMENTS}

Crocosphaera watsonii was grown in $500 \mathrm{~mL}+\mathrm{P}$ SO medium (as described above) to mid log phase and then equal volumes $(25 \mathrm{~mL})$ were dispensed into glass culture tubes. Arsenate was added to triplicate cultures at final concentrations of $0,15,30,150$, and $500 \mathrm{nM}$. The triplicate treatments were pooled and harvested by filtration $(0.2 \mu \mathrm{m}, 25 \mathrm{~mm}$ polycarbonate filters) after a $24 \mathrm{~h}$ incubation under the growth conditions detailed above. Samples were flash frozen immediately and later stored in liquid nitrogen for subsequent gene expression analyses. In similar experiments to assay nitrogen fixation, $30 \mathrm{~mL}$ of exponentially growing $+\mathrm{P}$ C. watsonii WH8501 cells were dispensed into 75-mL square polycarbonate culturing bottles. Arsenate was added to triplicate culture bottles at final concentrations of $0,15,30,150,500$, and $1000 \mathrm{nM}$ arsenate.

\section{PHOSPHORUS MANIPULATION EXPERIMENTS}

Triplicate $+\mathrm{P}(45 \mu \mathrm{M})$ cultures were grown as a scale up as described above and harvested at late log phase by centrifugation $(7000 \mathrm{rpm})$. The cell pellets were pooled and split into two equal volumes, washed twice in either $+\mathrm{P}$ or $-\mathrm{P}\left(-\mathrm{P} ; 1 \mu \mathrm{M} \mathrm{K}_{2} \mathrm{HPO}_{4}\right)$ medium to restrict carryover and resuspended in $25 \mathrm{~mL}$ of the same medium. The resulting $+\mathrm{P}$ and $-\mathrm{P}$ cell suspensions were divided among 3-500 mL flasks of like medium. Whole flasks were harvested onto polycarbonate filters $(47 \mathrm{~mm}, 0.2 \mu \mathrm{m})$ at $0,24,72$, and $120 \mathrm{~h}$ after resuspension and flash frozen in liquid nitrogen for subsequent analyses. In an additional experiment, triplicate $+\mathrm{P}$ and $-\mathrm{P}$ cultures were inoculated each with $2 \mathrm{~mL}$ P replete stock that had been centrifuged, split into two equal volumes, washed twice in either $+\mathrm{P}$ or $-\mathrm{P}$ medium and resuspended in $2 \mathrm{~mL}$ of the same medium. Cultures were harvested from mid log phase $+\mathrm{P}$ cultures. When growth had ceased in $-\mathrm{P}$ cultures, the triplicate cultures were pooled and split into six flasks. Triplicate cultures were re-fed with phosphate to replete P levels $(45 \mu \mathrm{M})$ and the remaining three were unchanged. Flasks were subsampled at 0,24 , $48,72,120$, and $168 \mathrm{~h}$ after phosphate addition, harvested onto polycarbonate filters $(25 \mathrm{~mm}, 0.2 \mu \mathrm{m})$, and flash frozen in liquid nitrogen for subsequent analyses.

\section{NITROGEN FIXATION}

Nitrogen fixation was assayed $24 \mathrm{~h}$ after the addition of arsenate (as described above), over the midpoint of the dark period 
in the incubator by the acetylene reduction assay described by Capone and Montoya (2001). Briefly, all culture bottle caps were replaced with silicone septa. Acetylene was produced by mixing $50 \mathrm{~mL}$ of MilliQ water with $15 \mathrm{~g}$ calcium carbide and stored in a bladder. Six milliliters of acetylene were injected into the bottles. At times 0, 30, 60, 90, and $120 \mathrm{~min}$ after injection, duplicate 0.4$\mathrm{mL}$ samples were removed from the headspace of the bottles and 0.3-mL samples were injected into a Shimadzu GC-8A gas chromatograph and integrated by a Shimadzu CR8A Chromatopac to measure the ethylene peaks. Standards of $9.1 \mathrm{ppm}$ ethylene were used to calibrate the peak heights. Ethylene formed was calculated according to Capone and Montoya (2001) with Bunsen coefficients calculated for a $75 \%$ seawater $25 \%$ MilliQ water mixture and ambient temperature according to Breitbarth et al. (2004). Nitrogenase activity was calculated as the average rate of ethylene production per volume $\left(\mathrm{nmol} \mathrm{C}_{2} \mathrm{H}_{4} \mathrm{~h}^{-1} \mathrm{~mL}^{-1}\right)$ with a ratio of $3: 1$. Growth of cultures was monitored by relative fluorescence with a Turner Designs Aquafluor fluorometer. The nitrogen fixation rate calculated for the control (no arsenate added) was set to one and the nitrogen fixation rates for different arsenate concentrations were compared as a proportion above or below the control.

\section{FIELD SAMPLE COLLECTION}

Samples were collected on board the R/V Bank of Bermuda Atlantic Explorer in the western North Atlantic (Figure 1) in 2006 on the BVAL37 transect from Bermuda to Puerto Rico. At each station,

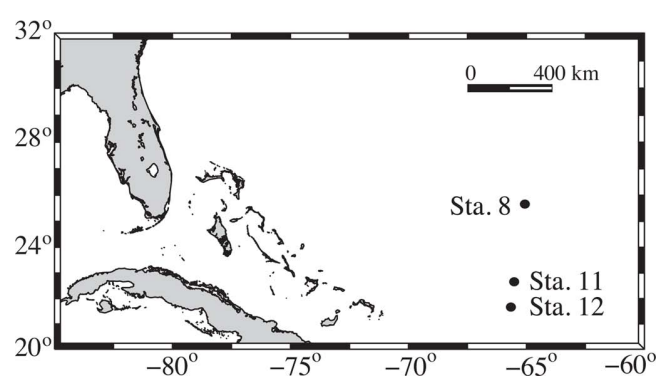

FIGURE 1 | Station locations for field samples collected from an October 2006 transect from north to south in the Sargasso Sea.
$12 \mathrm{~L}$ of near surface $(\sim 5 \mathrm{~m})$ seawater was collected via a Niskin bottle and filtered through $0.2 \mu \mathrm{m}$ Sterivex cartridge filters (Millipore) under low pressure. Samples were flash frozen and stored in liquid nitrogen prior to analyses. Total processing time from water to liquid nitrogen was roughly $20 \mathrm{~min}$. Dissolved inorganic phosphate (DIP) concentration was determined on Niskin-collected water from the same depth and analyzed as described elsewhere with a typical detection limit of $0.5 \mathrm{nM}$ (Lomas et al., 2010).

\section{TOTAL RNA EXTRACTION FROM CULTURE AND FIELD SAMPLES}

RNA extractions were performed on cultured C. watsonii WH8501 cells with the RNeasy Mini Kit (Qiagen, Valencia, CA, USA) with a small modification to the lysis procedure. Lysis was performed by adding $\sim 500 \mu \mathrm{l}$ zirconium/silica beads $(0.5 \mathrm{~mm})$ and vortexing for $10 \mathrm{~min}$ at $250 \mathrm{rpm}$. The RNA was then treated with Turbo DNase (Ambion, Austin, TX, USA) following the rigorous protocol to remove genomic DNA. RNA was quantified spectrophotometrically, and a total of $60 \mathrm{ng}$ of RNA was transcribed into cDNA using random hexamers included in the iScript cDNA Synthesis kit (BioRad, Hercules, CA, USA), according to the instructions. Additional reactions for each sample were set up without reverse transcriptase (RT) to ensure the absence of genomic DNA in no-RT controls.

RNA was extracted from field samples using the RNeasy Mini Kit (Qiagen) with minor modifications in the lysis procedure. Lysis was performed by adding $\sim 500 \mu \mathrm{l}$ zirconium/silica beads $(0.5 \mathrm{~mm})$, TE/lysozyme buffer $\left(15 \mathrm{mg} \mathrm{mL}^{-1}\right)$, and Buffer RLT (Qiagen) to the Sterivex cartridge. Cartridges were vortexed for $10 \mathrm{~min}$ at $250 \mathrm{rpm}$. The resulting lysate was removed through the Sterivex inlet with a syringe, transferred into a $15-\mathrm{mL}$ conical tube, and processed as per the remaining steps of the RNeasy protocol. Nucleic acid concentrations were quantified using a NanoDrop ${ }^{\circledR}$ ND-1000 spectrophotometer (NanoDrop Technologies, Wilmington, DE, USA). Field samples typically yielded $\sim 35 \mathrm{ng}$ total RNA. For the field samples, RNA was transcribed and amplified in one step (see below) using gene-specific primers (Table 1).

\section{GENE EXPRESSION}

Crocosphaera watsonii WH8501 culture samples were quantitatively assayed by qRT-PCR while field samples were qualitatively assayed by RT-PCR. Primer sets for $\operatorname{ars} B, p s t S$, and $\operatorname{rot} A$ (Table 1)

Table 1 | Primers and amplification conditions for the genes used in qRT-PCR and RT-PCR.

\begin{tabular}{|c|c|c|c|c|}
\hline Gene & Primer sequence & Accession number & Annealing temperature $\left({ }^{\circ} \mathrm{C}\right)$ & Amplicon size (bp) \\
\hline \multirow[t]{2}{*}{$\operatorname{ars} B$} & 5’ AACAATGGTTTGCCAGGGAAC & ZP_00514915 & $59.5^{\circ} \mathrm{C}$ & 116 \\
\hline & 3’ GTCATACTTTGGTGATGGTTGCG & & & \\
\hline \multirow[t]{2}{*}{ pstS } & 5' TTGTGCAACTCAACACAGCA & ZP_00514993 & $59.5^{\circ} \mathrm{C}$ & 127 \\
\hline & 3'TCTGTCATGGCCACATCACT & & & \\
\hline \multirow[t]{2}{*}{$\operatorname{rot} A$} & 5’ GAGAAGATGCTCCTATTACCGCC & ZP_00514036 & $59.5^{\circ} \mathrm{C}$ & 243 \\
\hline & 3' GTTGACCCAATGCTTTGCTGTAG & & & \\
\hline \multirow[t]{3}{*}{$p h n D^{a}$} & 5’ TCGGNGCMATYCCSGATCAGAACCCSG & & $65^{\circ} \mathrm{C}^{b}$ & 620 \\
\hline & 3’ TTGGGCTGSGCGASCCAGTGGTARTC & & & \\
\hline & 3’ GGNCGNGCCACCCAGTGGTARTC & & & \\
\hline
\end{tabular}

a Primers were designed by llikchyan et al. (2009).

${ }^{b}$ Decreased by $0.5^{\circ} \mathrm{C}$ each cycle until $55^{\circ} \mathrm{C}$ was reached, after llikchyan et al. (2009). 
were designed based on the sequenced genome of $C$. watsonii WH8501 ${ }^{1}$. Primers, designed and utilized by llikchyan et al. (2009), were used to amplify the Synechococcus spp. phnD gene encoding a putative phosphonate binding protein (Table 1). All analyses were performed in triplicate in an iCycler iQ Real-time PCR detection system (Bio-Rad) in a total volume of $25 \mu$ l. The reaction mix contained $12.5 \mu \mathrm{l}$ iQ SYBR Green Supermix (BioRad), $0.2 \mu \mathrm{M}$ primer concentrations, and $1 \mu \mathrm{l}$ template cDNA (diluted 1:10). Reactions were cycled using a temperature profile of $95^{\circ} \mathrm{C}$ for $5 \mathrm{~min}(1 \times), 95^{\circ} \mathrm{C}$ for $30 \mathrm{~s}(1 \times)$, and $59.5^{\circ} \mathrm{C}$ for $30 \mathrm{~s}$ $(45 \times)$. The temperature profile also included a melt curve protocol at the end of the program. In all cases, melt curves were used to confirm single amplification products for the different reactions. In addition, for each sample and primer pair no-RT controls and no template controls were run to test for DNA contamination and specificity of amplification. These negative controls did not typically amplify, but in the rare cases where there was any amplification the measured template concentration was at least two orders of magnitude less than the sample template concentration.

The comparative, or $\Delta \Delta \mathrm{Ct}$, method was used to normalize the expression of each gene for the qRT-PCR. The amplification efficiency and validation of the $\Delta \Delta \mathrm{Ct}$ method were tested for each primer set on cDNA. Amplification efficiency was determined to be acceptable if it fell between 90 and $110 \%$ with an $r^{2}$ of 0.98 or higher. Each primer pair was considered acceptable if the $\Delta \mathrm{Ct}$ of the two slopes was less than 0.1. Samples were normalized to the constitutively expressed rotA (ZP_00514036), encoding a peptidyl-prolyl cis-trans isomerase (Hassidim et al., 1992; Thellin et al., 1999). This gene has previously been used as a reference gene with the marine diazotroph Trichodesmium erythraeum (Orchard et al., 2009), and the Ct of this reference gene did not vary with plate or treatment in samples normalized to total RNA. Fold changes were calculated using the Relative Expression Software Tool, which accounts for differences in efficiency in its fold change calculation ${ }^{2}$. For each experiment a single $T_{0}$ time point sample was used as a calibrator for calculating fold changes. The $p$-values were calculated using a pair-wise fixed reallocation randomization analysis as noted (Pfaffl et al., 2002).

RT-PCR of environmental samples was performed using a OneStep-RT-PCR kit (Qiagen) according to the manufacturer's instructions. Briefly, the reaction mix contained RNase-free water, $5 \times$ OneStep-RT-PCR buffer, dNTP mix (containing $10 \mathrm{mM}$ of each dNTP), $0.6 \mu \mathrm{M}$ gene-specific primer concentrations (final), OneStep-RT-PCR enzyme mix, and template RNA ( $\sim 10 \mathrm{ng})$ for a total reaction volume of $20 \mu$ l. Reactions were cycled with a temperature profile of $50^{\circ} \mathrm{C}$ for $30 \mathrm{~min}(1 \times), 95^{\circ} \mathrm{C}$ for $15 \mathrm{~min}$ $(1 \times), 94^{\circ} \mathrm{C}$ for $30 \mathrm{~s}, 59.5^{\circ} \mathrm{C}$ for $30 \mathrm{~s}$, and $72^{\circ} \mathrm{C}$ for $1 \min (40 \times)$, and $72^{\circ} \mathrm{C}$ for $10 \mathrm{~min}$. To validate the integrity of the extracted RNA, Synechococcus spp. phnD amplification was included for each environmental sample. The temperature profile was the same for the reverse transcription and initial PCR activation steps. However, the temperature profile for amplification was modified to

\footnotetext{
${ }^{1}$ http://img.jgi.doe.gov/pub/main.cgi

${ }^{2} \mathrm{http}$ ://www.gene-quantification.de/download.html
}

$95^{\circ} \mathrm{C}$ for $5 \mathrm{~min}(1 \times), 95^{\circ} \mathrm{C}$ for $1 \mathrm{~min}$, an initial annealing temperature of $65^{\circ} \mathrm{C}$ for $1 \mathrm{~min}$ decreasing by $0.5^{\circ} \mathrm{C}$ each cycle until $55^{\circ} \mathrm{C}$ was reached, and $72^{\circ} \mathrm{C}$ for $1 \mathrm{~min}(40 \times)$, and extension at $72^{\circ} \mathrm{C}$ for $20 \mathrm{~min}$ (Ilikchyan et al., 2009). Additionally, reactions were performed without RT to ensure the absence of genomic DNA in the RNA samples. RT-PCR products were resolved on $2 \%$ agarose gels. Selected bands were identified, excised, and gel purified using the QIAquick gel extraction kit (Qiagen). Sequencing of PCR products was performed at the University of Maine Sequencing Facility (Orono, ME). All sequence data were analyzed manually using the programs Sequencher (Gene Codes Corporation, Ann Arbor, MI, USA), MacVector (Accelrys, Burlington, MA, USA), and BLASTN ${ }^{3}$. The sequence of the field amplicon has been deposited in the EMBL Nucleotide Sequence Database ${ }^{4}$ with accession number FR873108.

\section{RESULTS \\ GENOMIC OBSERVATIONS}

The genome of $C$. watsonii WH8501 contains homologs for genes involved in the reduction of arsenate to arsenite and the pumping of arsenite out of the cell (Figure 2). A homolog of an arsenite efflux pump, arsB (ZP_00514915) and an arsenate reductase, arsC (ZP_00514912), are present in the C. watsonii genome (Figure 2). These genes are separated by two genes, ars $H$ and ars $H^{\prime}$, encoding proteins of unknown function (Figure 2). The arsA (ZP_00516616) gene, an arsenical pump-driving ATPase, is $87.82 \%$ identical to Synechococcus PCC 6803. In both Synechococcus PCC 6803 and C. watsonii WH8501 arsA is not contiguous to the other ars genes, and in C. watsonii WH8501 it is isolated on a relatively small contig. The $C$. watsonii WH8501 genome also contains the $p s t S C A B$ genes that encode a high-affinity $\mathrm{P}$ transport system and an additional putative low affinity phosphate permease (Dyhrman and Haley, 2006).

\section{ARSENATE ADDITION EFFECTS ON GROWTH AND NITROGEN FIXATION}

Different concentrations of arsenate were added to C. watsonii WH8501 cultures to measure the effect on growth in combination with two different phosphate concentrations. Growth rates were calculated for each biological replicate (e.g., each flask) and then averaged within a treatment. The growth rate calculated for the

\footnotetext{
${ }^{3} \mathrm{http} / / /$ www.ncbi.nlm.nih.gov/BLAST

${ }^{4} \mathrm{http}: / /$ www.ebi.ac.uk/embl/
}

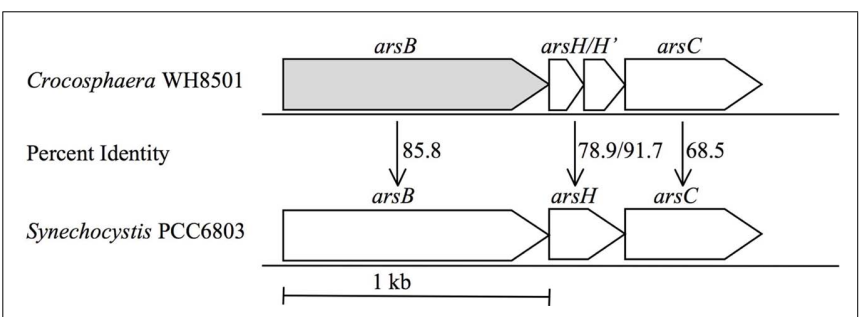

FIGURE 2 |The gene topology of $C$. watsonii WH8501 arsCHB and percent identity to Synechocystis PCC6803. Genes shaded gray have been shown to be up-regulated by phosphorus stress, or arsenate addition in this study. 
Replete control (no arsenate added, $45 \mu \mathrm{M}$ phosphate) was set to one and the growth rate for different arsenate and phosphate concentrations were normalized to the Replete growth rate. Significant differences in normalized growth rates were found in different treatments (Figure 3A, one-way ANOVA, $p<0.0001$ ). Post hoc testing at the $p<0.05$ level (Student Newman-Keuls) found no significant differences in normalized growth rate between the Replete and the cultures grown with no added arsenate, regardless of added phosphate concentration, although yield on day 8 of the experiment was highest in the Replete treatment (Figure 3B). All treatments with added arsenate had normalized growth rates significantly lower than the Replete. Four arsenate addition levels were replicated with and without added phosphate; a 2-way ANOVA using these arsenate and phosphate concentrations as factors found no significant effect of phosphate concentration on normalized growth rate $(p=0.3341$; Figure 3A). However, increasing arsenate concentration had a highly significant effect on normalized growth rate $(p<0.0001$; Figure 3A). There was no significant interaction effect between phosphate and arsenate $(p=0.9051)$. For the cultures with NoP $(0 \mathrm{nM}-$ typically $\sim 5 \mathrm{nM}$ residual phosphate in culture medium), growth rates were depressed in the 15- and 30-nM treatments (Figure 3A). The transition from positive growth to negative growth occurred with an arsenate addition between 30 and $150 \mathrm{nM}$ (Figure 3A). Short-term $(24 \mathrm{~h})$ additions of arsenate in concentrations of $0,15,30,150$, 500 , and $1000 \mathrm{nM}$ had no affect on in vivo fluorescence (data not shown). Further, these same arsenate additions had no acute effect (one-way ANOVA, $p=0.9816$ ) on nitrogen fixation rate after $24 \mathrm{~h}$ (Figure 4).

\section{GENE EXPRESSION PATTERNS}

In $+\mathrm{P}$ cultures of $C$. watsonii WH8501, expression of arsB was higher, and statistically different from the no addition control with the addition of $30 \mathrm{nM}(p=0.000$; Figure 5). In this experiment, fold changes increased as a function of increasing arsenate (Figure 5). The expression of arsB was higher in $-\mathrm{P}$ cultures of
C. watsonii WH8501 relative to the $+\mathrm{P}$ control by $72 \mathrm{~h}(p=0.000)$, and further increased by $120 \mathrm{~h}$ (Figure 6). Consistent with previous work (Dyhrman and Haley, 2006), the expression of pstS in the $-\mathrm{P}$ cultures was statistically higher than in the $+\mathrm{P}$ cultures by $120 \mathrm{~h}(p=0.000)$, although overall expression levels of $p s t S$ were low relative to ars $B$ (Figure 6). When $\mathrm{P}$ was re-supplied to P-stressed cultures, $\operatorname{ars} B(p=0.000)$, and $p s t S(p=0.012$; data not shown) were statistically lower within $48 \mathrm{~h}$ and remained low ( $a r s B ; p=0.013$ and $p s t S ; p=0.044$ ) over the course of the 168-h experiment (Figure 7).

\section{FIELD DETECTION OF C. watsonii ARSB}

Three near surface samples were examined for the expression of the $C$. watsonii ars $B$ gene in an oligotrophic region of the western North Atlantic during a transect from Bermuda to Puerto Rico in October 2006 (BVAL 37). The field stations examined had DIP concentrations $<10 \mathrm{nM}$ (Table 2). A $C$. watsonii arsB transcript was detected at station 12 , and confirmed with sequencing of the amplicon, which was $100 \%$ identical to the arsB WH8501 genome sequence. $C$. watsonii ars $B$ transcripts were not detected at stations 8 and 11. Amplification was not observed in the no-RT controls for the stations tested, and expression of the Synechococcus sp. phnD transcript was detected at all stations (Table 2).

\section{DISCUSSION}

Arsenate is common in the ocean with surface water concentrations from approximately 5-20 nM (Andreae, 1979; Cutter and Cutter, 1995). Arsenate and phosphate share the same oxidative state and as a consequence, enzymes, and proteins may bind arsenate and move it into the cell by phosphate transport systems with little selectivity (Tawfik and Viola, 2011). Although some microbes thrive in high arsenate (Brunskill et al., 1980; Thiel, 1988; LópezMaury et al., 2003), marine microorganisms, which must take up phosphate to supply their metabolic needs, face a unique problem in oligotrophic regimes, where phosphate concentrations are low and arsenate may equal or exceed the phosphate concentration

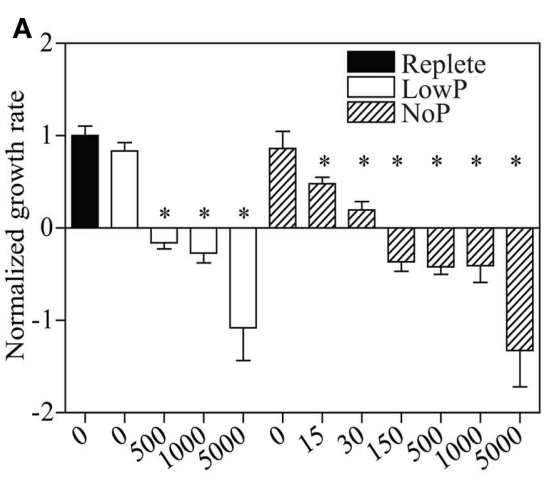

Concentration As (nM) added

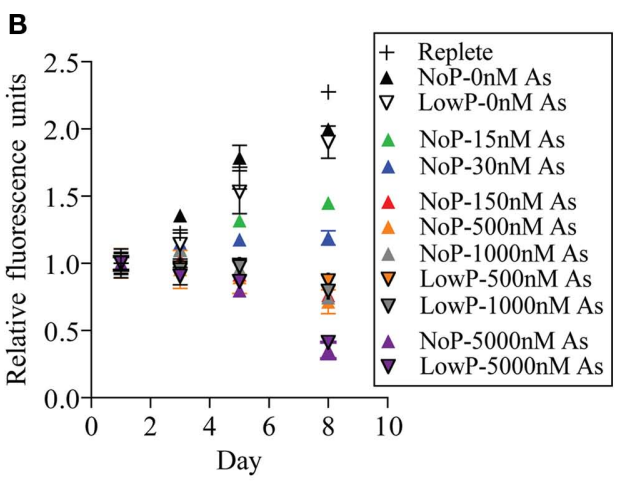

FIGURE 3 | C. watsonii WH8501 growth responses to arsenate (As). (A) Growth rate of $C$. watsonii WH8501 normalized to the Replete control with $45 \mu \mathrm{M}$ phosphate (P) and no added As. Treatments consisted of different concentrations of As added to medium with either LowP (500 $\mathrm{nM})$ or NoP. Error bars are the SE of the mean $(n=3)$. Significantly lower growth rates from the Replete control $(p<0.05)$ are indicated $\left(^{*}\right)$ for each treatment using a 1-way ANOVA. (B) C. watsonii WH8501 relative fluorescence as a function of day in growth curves for each $P$ and as treatment. Treatment key is ordered by the yield on day 8. Error bars are the SE of the mean $(n=3)$. 


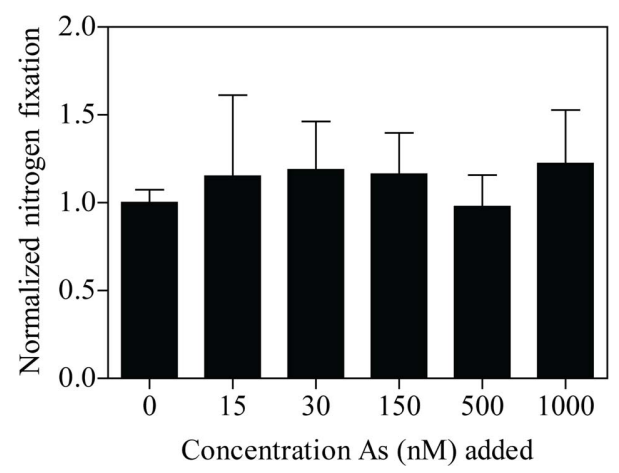

FIGURE 4 | Nitrogenase activity of $C$. watsonii WH8501 normalized to the control with no added arsenate. Treatments consisted of different concentrations of added arsenate as indicated. Error bars indicate the SE of the mean $(n=3)$.

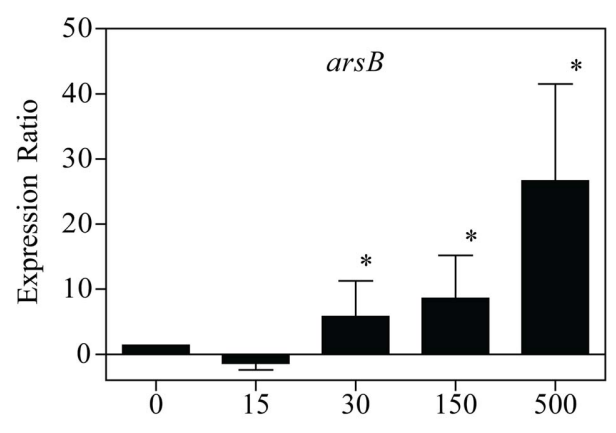

Concentration of As (nM) added

FIGURE 5 | Expression pattern for ars $B$ as a function of arsenate additions. The expression ratio is the fold change of triplicate measurements between the sample expression and the calibrator expression (e.g., the zero time point). Error bars indicate the SE of triplicate measurements of the expression ratio. Significance $(p<0.05)$ is indicated $\left.{ }^{*}\right)$ for each arsenate addition treatment relative to the no addition control using a pair-wise fixed reallocation randomization analysis.

(Johnson and Pilson, 1972). Nitrogen-fixing marine cyanobacteria are often present in low phosphate environments, and exhibit evidence of $\mathrm{P}$ stress-induced adaptations in some regions like the western North Atlantic (Dyhrman et al., 2002, 2007; Dyhrman and Haley, 2006). It has also been hypothesized that they may draw down phosphate to the extent that they induce phosphate deficiency in local microbial populations (Hewson et al., 2009b). In these systems, cellular arsenate resistance strategies would allow diazotrophs to ameliorate the effects of arsenate transport into the cell.

Despite the potential coupling between arsenate and phosphate cycling in marine waters, relatively little is known about arsenate resistance in the nitrogen-fixing marine cyanobacteria that are common in oligotrophic systems. The unicellular diazotroph, C. watsonii WH8501, was able to grow, but with reduced rates, with arsenate additions up to $30 \mathrm{nM}$, and estimated arsenate to phosphate ratios up to $6: 1$. Cell abundance declined rapidly in

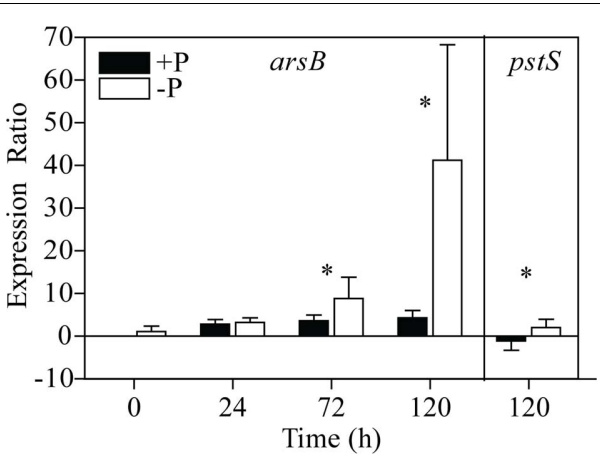

FIGURE 6 | Expression patterns for arsB and pstS in cultures transferred into either phosphate replete $(+P)$ or no added $P(-P)$ medium. The expression ratio is the fold change of triplicate measurements between the sample expression and the calibrator expression (e.g., the zero time point). Error bars indicate the SE of triplicate measurements of the expression ratio. Significance $(p<0.05)$ is indicated $(*)$ for the $-P$ versus the $+P$ culture at a single time point for pair-wise fixed reallocation randomization analysis.

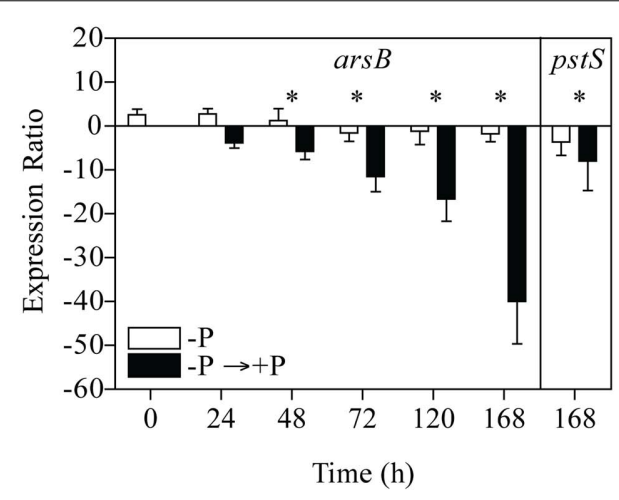

FIGURE 7 | Expression patterns for arsB and pstS in phosphate deficient cultures $(-\mathbf{P})$ re-fed with phosphate $(+\mathbf{P})$. The expression ratio is the fold change of triplicate measurements between the sample expression and the calibrator expression (e.g., the zero time point). Error bars indicate the SE of triplicate measurements of the expression ratio. Significance $(p<0.05)$ is indicated $\left(^{*}\right)$ for the $-\mathrm{P}$ versus the re-fed culture at a single time point for pair-wise fixed reallocation randomization analysis.

treatments with $500 \mathrm{nM}$ arsenate and phosphate together at a 1:1 ratio, suggesting that $C$. watsonii is sensitive to the absolute concentration of arsenate and not simply the arsenate to phosphate ratio. Several cyanobacterial species, such as Anabaena variabilis and Synechocystis strain PCC6803 are able to grow in the presence of high concentrations of arsenate (up to $75 \mathrm{mM}$ ) and in lowmillimolar concentrations of arsenite, respectively (Thiel, 1988; López-Maury et al., 2003). At this juncture, C. watsonii WH8501 appears to be more sensitive to arsenate additions, ceasing net growth with additions of $500 \mathrm{nM}$ arsenate in medium with $500 \mathrm{nM}$ phosphate, and with additions of only $30 \mathrm{nM}$ arsenate in medium made from low phosphate Sargasso Sea seawater with no added P. The selectivity of phosphate transporters for phosphate relative to arsenate can be variable (Budd and Craig, 1981; Takahashi et al., 2001; Tawfik and Viola, 2011) and was not examined herein, but 
Table 2 | Presence or absence of Crocosphaera watsonii arsB, arsB no-RT, and Synechococcus spp. phnD in field samples.

\begin{tabular}{|c|c|c|c|c|}
\hline Cruise-station ID & $\operatorname{ars} B$ & $\operatorname{ars} B$ no-RT & phnD & DIP (nM) \\
\hline BVAL37-8 & - & - & + & 5.4 \\
\hline BVAL37-11 & - & ND & + & 2.7 \\
\hline BVAL37-12 & + & - & + & BLD \\
\hline
\end{tabular}

$N D$, not determined - there was not enough template for this sample to perform a no-RT reaction for arsB; DIP, Dissolved inorganic phosphate; BLD, Below detection limit.

these growth data suggest that arsenate is able to enter the cell and effect net growth rate in both $0 \mathrm{nM}$ added and $500 \mathrm{nM}$ added phosphate treatments. Phosphate may be transported by $C$. watsonii WH8501 using a low affinity phosphate permease system under high phosphate, and via the canonical pstSCAB high-affinity system under low phosphate (Dyhrman and Haley, 2006). These growth data are consistent with this hypothesis, given that the arsenate exhibited toxic effects on growth and was likely transported into the cells in both the 500- and 0-nM treatments. This is also consistent with the sensitivity of $C$. watsonii to arsenate compared to other cyanobacteria, as the putative low affinity phosphate permease transport system is not common in the other marine cyanobacteria (Dyhrman and Haley, 2006).

Arsenate metabolism and the related genes are well studied in a diverse array of microbes (Stolz et al., 2006). A conserved strategy for arsenate detoxification among the marine picocyanobacteria examined to date is the reduction of arsenate to arsenite within the cell by means of an arsenate reductase and subsequent removal by an arsenite efflux pump (ArsB; Scanlan et al., 2009). The required genes are broadly distributed in the marine picocyanobacteria Prochlorococcus and Synechococcus (Scanlan et al., 2009). The arsenate resistance genes are also present in C. watsonii WH8501, which has homologs for ars $A$ and $\operatorname{ars} C H H^{\prime} B$. The ars $A$ gene is not contiguous with the other ars genes in the genome. It encodes an arsenical pump-driving ATPase, ars $C$ encodes a putative arsenate reductase, and $a r s B$ encodes the arsenite efflux pump. The ArsH protein has been shown to be required for resistance to arsenite and arsenate in some bacteria, such as Yersinia enterocolitica (Neyt et al., 1997), and arsH is present in the arsBHC operon involved in arsenic resistance in the cyanobacteria Synechocystis sp. PCC6803 (López-Maury et al., 2003), but its role in detoxification is unknown.

The short-term addition of arsenate to high phosphate cultures of C. watsonii WH8501 resulted in the up-regulation of the arsB gene, demonstrating its responsiveness to arsenate. Expression levels were titered to increasing arsenate concentration, indicating the induction of an arsenate detoxification response that is sensitive to absolute concentration of arsenate. Although ars $B$ was significantly induced with arsenate additions of $30 \mathrm{nM}$ or greater, arsenate did not result in acute effect on growth or nitrogen fixation over the 24-h incubation. In fact, there may be no acute effect on nitrogen fixation because C. watsonii WH8501 is able to detoxify arsenate. Given the growth responses to longer-term arsenate exposure highlighted above, there is likely an effect on nitrogen fixation in scenarios of chronic exposure, or where the arsenate resistance system is unable to compensate. This could be the result of arsenic accumulation in the cell, which has been shown to occur with chronic exposure in other phytoplankton (Sanders and Windom, 1980). As such, arsenate toxicity could be a controlling factor on nitrogen fixation in areas where the arsenate to phosphate ratio, or the absolute arsenate concentration, is chronically high. Regardless, C. watsonii WH8501 clearly induces arsB in response to even low arsenate additions, which underscores the sensitivity of the resistance response to arsenate.

The ars $B$ expression patterns examined herein demonstrate that the gene is concomitantly expressed during $\mathrm{P}$ stress with $p s t S$. The differences in the ars $B$ and $p s t S$ expression ratios, are consistent with the heterogeneity observed between P-responsive genes in T. erythraeum (Orchard et al., 2009), and likely reflect different transcript abundances. Expression levels of both genes decline upon $\mathrm{P}$ addition to phosphate deficient cells within $48 \mathrm{~h}$. This is somewhat slower than what is observed with Prochlorococcus strains (Martiny et al., 2006), and the diazotroph T. erythraeum (Orchard et al., 2009), which may be related to the relatively slow doubling times ( $\sim 40-60 \mathrm{~h}$ ) reported for $C$. watsonii strains (Webb et al., 2009). Although the arsB gene is clearly induced in concert with pstS, a known phosphate-responsive phosphate binding protein gene, the ars $\mathrm{B}$ in this case may be responsive to the changing arsenate uptake dynamics driven by changes in the expression of the high-affinity phosphate transport system, and the arsenate to phosphate ratio in the medium, rather than as a direct response to phosphate supply.

Unicellular diazotrophs such as C. watsonii are increasingly recognized for their contribution to oceanic nitrogen fixation (Zehr et al., 2001; Montoya et al., 2004), despite their low abundance. This low abundance makes tracking C. watsonii gene expression patterns in the field a challenge relative to more abundant picocyanobacteria. For example, even at its highest cell densities in C. watsonii bloom scenarios, relatively few C. watsonii transcripts could be detected in metadata sets (Hewson et al., 2009a). Low field abundances have thus, in part, restricted transcriptomic studies of this diazotroph in the field to surveys of nifH transcripts and the one metatranscriptomic study in a high density population highlighted above (Hewson et al., 2009a). Herein, we observed expression of $C$. watsonii ars $B$ in the near surface waters of the tropical western North Atlantic. The likely explanation for why two of the three stations did not have a detectable C. watsonii ars $B$ amplicon is low cell abundance, since estimated cell density in this general region of the western North Atlantic is both spatially variable and low; ranging from undetectable to about seven C. watsonii nifH copies $\mathrm{L}^{-1}$ (Langolis et al., 2008; Moisander et al., 2010). C. watsonii abundance was not examined on the transect, but Synechococcus abundances in this region averaged $10^{4}$ cells $\mathrm{mL}^{-1}$ in surface waters (Casey et al., 2009), much higher than 
typical C. watsonii abundances $\left(<<10^{3}\right.$ cells $\left.\mathrm{mL}^{-1}\right)$. The fact that the samples amplified for Synechococcus sp. phnD suggests that the RNA was of good quality, and either $C$. watsonii ars $B$ was not expressed, or $C$. watsonii was not present at abundances where ars $B$ transcripts could be detected. Despite these challenges, the arsB transcript detected at station 12 was clearly from C. watsonii. Without quantitative data we are unable to ascertain if this transcript was induced to levels that would suggest substantial arsenate detoxification, however, the expression of ars $B$ is consistent with the detection of the arsenite detoxification product in the North Atlantic (Andreae and Klumpp, 1979; Sanders and Windom, 1980).

The expression of arsenate detoxification genes has not been comprehensively examined in marine microbial populations, although expression of arsenate reductase, $\operatorname{ars} A$, and $\operatorname{ars} B$ were detected in metatranscriptome data from a Trichodesmium consortium collected from the South Pacific (Hewson et al., 2009b). In this case, the ars $A$ was from Trichodesmium, and the other signals were from other heterotrophic bacteria present in the sample (Hewson et al., 2009b). The presence of these transcripts in the relatively high phosphate environment of the South Pacific may be attributed to changes in $\mathrm{P}$ cycling driven by a dense population of diazotrophs (Hewson et al., 2009b), and/or differences in the sensitivity of different microbes to arsenate toxicity. Of the very few $C$. watsonii transcripts detected in this study, none were related to arsenate detoxification (Hewson et al., 2009b). The arsB transcript was also not detected in the metatranscriptome of a bloom of C. watsonii in the South Pacific (Hewson et al., 2009a). The detection of $C$. watsonii arsB in the western North Atlantic and not the South Pacific is consistent with the relatively high phosphate environment of the South Pacific relative to the western North Atlantic. However it is difficult to cross-compare between

\section{REFERENCES}

Andersen, R. A., Jacobson, D. M., and Sexton, J. P. (1991). ProvasoliGuillard Center for Culture of Marine Phytoplankton: catalogue of strains. Provasoli-Guillard Center for Culture of Marine Phytoplankton: West Boothbay Harbor, ME.

Andreae, M. O. (1979). Arsenic speciation in seawater and interstitial waters: the influence of biological-chemical interactions on the chemistry of a trace element. Limnol. Oceanogr. 24, 440-452.

Andreae, M. O., and Klumpp, D. W. (1979). Biosynthesis and release of organoarsenic compounds by marine algae. Environ. Sci. Technol. 13, 738-741.

Apte, S. C., Howard, A. G., Morris, R. J., and McCartney, M. J. (1986). Arsenic, antimony and selenium speciation during a spring phytoplankton bloom in a closed experimental ecosystem. Mar. Chem. 20, 119-130.

Bleeker, P. M., Schat, H., Vooijs, R., Verkleij, J. A. C., and Ernst, W. H.

PCR and metatranscriptome studies because of differences in the sensitivities of the two methods, and the lack of quantitative data. Regardless, the field detection ars $B$ in the western North Atlantic is permissive of the induction of $C$. watsonii arsenate detoxification strategies in this low phosphate environment.

More detailed, quantitative studies that track the expression of $\operatorname{ars} B$, and rates of arsenate reduction are required to examine coupling between the cycling of phosphate and arsenate in diazotrophs like C. watsonii in the field, and to determine the impact of phosphate and arsenate supply on $C$. watsonii growth and nitrogen fixation in situ. However, the data presented herein are a first step toward these more detailed characterization studies. Taken together, these data identify that $C$. watsonii has an arsenate resistance strategy that is sensitive to changes in arsenate, and phosphate concentration. Chronic arsenate exposure may reduce growth rates despite the presence of a detoxification mechanism in this group of diazotrophs, and the expression of C. watsonii ars $B$ in the western North Atlantic suggests that the coupling of the arsenate and phosphate cycles should be examined in greater detail in oligotrophic marine systems.

\section{ACKNOWLEDGMENTS}

The authors thank Dr. Elizabeth Orchard (WHOI), Dr. Mike Lomas (BIOS), Dr. Andrew Juhl (LDEO), and Dr. Louie Wurch (WHOI) for helpful discussions and assistance. The authors also thank the captain and crew of the $R / V$ Bank of Bermuda Atlantic Explorer for assistance at sea, as well as Harriet Alexander (WHOI) for generating the cruise transect map. Special thanks are due to Abigail Heithoff (WHOI) for conducting nitrogen fixation measurements. This research was funded in part by the National Science Foundation \#OCE-0451419, and the Center for Microbial Oceanography: Research and Education.

Capone, D. G., and Montoya, J. P. (2001). "Nitrogen fixation and denitrification," in Methods in Microbiology, ed. J. Paul (San Diego, CA: Academic), 501-515.

Casey, J. R., Lomas, M. W., Michelou, V. K., Dyhrman, S. T., Orchard, E. D., Ammerman, J. W., and Sylvan, J. B. (2009). Phytoplankton taxon-specific orthophosphate $(\mathrm{Pi})$ and ATP utilization in the western subtropical North Atlantic. Aquat. Microb. Ecol. 58, 31-44.

Church, M. J., Jenkins, B. D., Karl, D. M., and Zehr, J. P. (2005). Vertical distributions of nitrogen-fixing phylotypes at Stn ALOHA in the oligotrophic North Pacific Ocean. Aquat. Microb. Ecol. 38, 3-14.

Coleman, M. L., and Chisholm, S. W. (2010). Ecosystem-specific selection pressures revealed through comparative population genomics. Proc. Natl. Acad. Sci. U.S.A. 107, 18634-18639.

Cutter, G. A., and Cutter, L. S. (1995). Behavior of dissolved antimony, arsenic, and selenium in the Atlantic Ocean. Mar. Chem. 49, 295-306.
Cutter, G. A., and Cutter, L. S. (2006). Biogeochemistry of arsenic and antimony in the North Pacific Ocean. Geochem. Geophys. Geosy. 7, Q05M08.

Dyhrman, S. T., Ammerman, J. W., and Van Mooy, B. A. S. (2007) Microbes and the marine phosphorus cycle. Oceanography 20, 110-116.

Dyhrman, S. T., and Haley, S. T. (2006). Phosphorus scavenging in the unicellular marine diazotroph Crocosphaera watsonii. Appl. Environ. Microbiol. 72, 1452-1458.

Dyhrman, S. T., Webb, E. A., Anderson, D. M. A., Moffett, J. W., and Waterbury, J. B. (2002). Cell-specific detection of phosphorus stress in Trichodesmium from the Western North Atlantic. Limnol. Oceanogr. 47, 1832-1836.

Falcón, L. I., Carpenter, E. J., Cipriano, F., Bergman, B., and Capone, D. G. (2004). N2-fixation by unicellular bacterioplankton from the Atlantic and Pacific Oceans: phylogeny and in situ rates. Appl. Environ. Microbiol. 70, 765-770. 
Falcón, L. I., Cipriano, F., Chistoserdov, A. Y., and Carpenter, E. J. (2002). Diversity of diazotrophic unicellular cyanobacteria in the tropical North Atlantic Ocean. Appl. Environ. Microbiol. 68, 5760-5764.

Hassidim, M., Schwarz, R., LiemanHurwitz, J., Marco, E., RonenTarazi, M., and Kaplan, A. (1992). A cyanobacterial gene encoding peptidyl-prolyl cis-trans isomerase. Plant Physiol. 100, 1982-1986.

Hewson, I., Moisander, P. H., Achilles, K. M., Carlson, C. A., Jenkins, B. D., Mondragon, E. A., Morrison, A. E., and Zehr, J. P. (2007). Characteristics of diazotrophs in surface to abyssopelagic waters of the Sargasso Sea. Aquat. Microb. Ecol. 46, 15-30.

Hewson, I., Poretsky, R. S., Beinhart, R. A., White, A. E., Shi, T., Bench, S. R., Moisander, P. H., Paerl, R. W., Tripp, H. J., Montoya, J. P., Moran, M. A., and Zehr, J. P. (2009a). In situ transcriptomic analysis of the globally important keystone $\mathrm{N}_{2}$-fixing taxon Crocosphaera watsonii. ISME J. 3, 618-631.

Hewson, I., Poretsky, R. S., Dyhrman, S. T., Zielinski, B., White, A. E., Tripp, H. J., Montoya, J. P., and Zehr, J. P. (2009b). Microbial community gene expression within colonies of the diazotroph, Trichodesmium, from the Southwest Pacific Ocean. ISME J. 3, 1286-1300.

Ilikchyan, I. N., McKay, R. M. L., Zehr, J. P., Dyhrman, S. T., and Bullerjahn, G. S. (2009). Detection and expression of the phosphonate transporter gene phnD in marine and freshwater picocyanobacteria. Environ. Microbiol. 11, 1314-1324.

Jakuba, R. W., Moffett, J. W., and Dyhrman, S. T. (2008). Evidence for the linked biogeochemical cycling of zinc, cobalt, and phosphorus in the western North Atlantic Ocean. Global Biogeochem. Cycles 22, GB4012.

Johnson, D. L., and Pilson, M. E. Q. (1972). Arsenate in the Western North Atlantic and adjacent regions. J. Mar. Res. 30, 140-148.

Langolis, R. J., Hümmer, D., and LaRoche, J. (2008). Abundances and distributions of the dominant nifH phylotypes in the Northern Atlantic Ocean. Appl. Environ. Microbiol. 74, 1922-1931.

Lomas, M. W., Burkel, A. L., Lomas, D. A., Bell, D. W., Shen, C., Dyhrman,
S. T., and Ammerman, J. W. (2010). Sargasso Sea phosphorus biogeochemistry: an important role for dissolved organic phosphorus (DOP). Biogeosciences 7, 695-710.

López-Maury, L., Florencio, F. J., and Reyes, J. C. (2003). Arsenic sensing and resistance system in the cyanobacterium Synechocystis sp. strain PCC 6803. J. Bacteriol. 185, 5363-5371.

Manomita, P. M., Bhowmik, N., Bandopadhyay, B., and Sharma, A. (2004). Comparison of mercury, lead and arsenic with respect to genotoxic effects on plant systems and the development of genetic tolerance. Environ. Exp. Bot. 52, 199-223.

Martiny, A. C., Coleman, M. L., and Chisholm, S. W. (2006). Phosphate acquisition genes in Prochlorococcus ecotypes: evidence for genomewide adaptation. Proc. Natl. Acad. Sci. U.S.A. 103, 12552-12557.

Moisander, P. H., Beinhart, R. A., Hewson, I., White, A. E., Johnson, K. S., Carlson, C. A., Montoya, J. P., and Zehr, J. P. (2010). Unicellular cyanobacterial distributions broaden the oceanic $\mathrm{N}_{2}$ fixation domain. Science 327, 1512-1514.

Montoya, J. P., Holl, C. M., Zehr, J. P., Hansen, A., Villareal, T., and Capone, D. G. (2004). High rates of $\mathrm{N}_{2}$ fixation by unicellular diazotrophs in the oligotrophic Pacific Ocean. Nature 430, 1027-1031.

Mukhopadhyay, R., Rosen, B. P., Phung, L. T., and Silver, S. (2002). Microbial arsenic: from geocycles to genes and enzymes. FEMS Microbiol. Rev. 26, 311-325.

Neyt, C., Iriarte, M., Thi, V. H., and Cornelis, G. R. (1997). Virulence and arsenic resistance in Yersinia. J. Bacteriol. 79, 612-619.

Orchard, E. D., Webb, E. A., and Dyhrman, S. T. (2009). Molecular analysis of the phosphorus starvation response in Trichodesmium spp. Environ. Microbiol. 11, 2400-2411.

Ordóñez, E., Letek, M., Valbuena, N., Gil, J. A., and Mateos, L. M. (2005). Analysis of genes involved in arsenic resistance in Corynebacterium glutamicum ATCC 13032. Appl. Environ. Microbiol. 71, 6206-6215.

Pfaffl, M. W., Horgan, G., and Leo, D. (2002). Relative expression software tool (REST) for group wise comparison and statistical analysis of relative expression results in real-time PCR. Nucleic Acids Res. 30, E36.

Rosen, B. P. (1999). Families of arsenic transporters. Trends Microbiol. 7, 207-212.

Sanders, J. G., and Windom, H. L. (1980). The uptake and reduction of arsenic species by marine algae. Estuarine Coastal Mar. Sci. 10, 555-567.

Scanlan, D. J., Ostrowski, M., Mazard, S., Dufresne, A., Garczarek, L., Hess, W. R., Post, A. F., Hagemann, M., Paulsen, I., and Partensky, F. (2009). Ecological genomics of marine picocyanobacteria. Microbiol. Mol. Biol. Rev. 73, 249-299.

Silver, S., and Phung, L. T. (2005). Genes and enzymes involved in bacterial oxidation and reduction of inorganic arsenic. Appl. Environ. Microbiol. 71, 599-608.

Smedley, P. L., and Kinniburgh, D. G. (2002). Phosphate transport and arsenate resistance in the cyanobacterium Anabaena variabilis. Appl. Geochem. 17, 517-568.

Statham, P. J., Burton, J. D., and Maher, W. A. (1987). Dissolved arsenic in waters of the Cape Basin. Deep Sea Res. A 34, 1353-1359.

Stolz, J. F., Basu, P., Santini, J. M. and Oremland, R. S. (2006). Arsenic and selenium microbial metabolism. Annu. Rev. Microbiol. 60, 107-130.

Takahashi, A., Kawakami, H., Iwakiri, K., and Matsuto, S. (2001). Some characteristics of arsenate transport in a marine cyanobacterium, Synechococcus sp. Appl. Organomet. Chem. 15, 291-298.

Tawfik, D. S., and Viola, R. E. (2011). Arsenate placing phosphate: alternative life chemistries and ion promiscuity. Biochemistry 50, 1128-1134.

Thellin, O., Zorzi, W., Lakaye, B., De Borman, B., Coumans, B., Hennen, G., Grisar, T., Igout, A., and Heinen, E. (1999). Housekeeping genes as internal standards: use and limits. $J$. Biotechnol. 75, 291-295.

Thiel, T. (1988). Phosphate transport and arsenate resistance in the cyanobacterium Anabaena variabilis. J. Bacteriol. 170, 1143-1147.

Wängberg, S.-Å., and Blanck, H. (1990). Arsenate sensitivity in marine periphyton communities established under various nutrient regimes. $J$. Exp. Mar. Biol. Ecol. 139, 119-134.

Waterbury, J. B., Valois, F. W., and Franks, D. G. (1986). "Biological and ecological characterization of the marine unicellular cyanobacterium Synechococcus," in Photosynthetic Picoplankton, eds T. Platt and W. K. W. Li (Ottawa: Canadian Department of Fisheries and Oceans), 71-120.

Webb, E. A., Ehrenreich, I. M., Brown, S. L., Valois, F. W., and Waterbury, J. B. (2009). Phenotypic and genotypic characterization of multiple strains of the diazotrophic cyanobacterium, Crocosphaera watsonii, isolated from the open ocean. Environ. Microbiol. 11, 338-348.

Wu, J., Sunda, W., Boyle, E. A., and Karl, D. M. (2000). Phosphate depletion in the western North Atlantic Ocean. Science 289, 759-762.

Zehr, J. P., Montoya, J. P., Jenkins, B. D., Hewson, I., Mondragon, E., Short, C. M., Church, M. J., Hansen, A. and Karl, D. M. (2007). Experiments linking nitrogenase gene expression to nitrogen fixation in the North Pacific subtropical gyre. Limnol. Oceanogr. 52, 169-183.

Zehr, J. P., Waterbury, J., Turner, P. J., Montoya, J. P., Omoregie, E., Steward, G. F., Hansen, A., and Karl, D. M. (2001). Unicellular cyanobacteria fix $\mathrm{N}_{2}$ in the subtropical North Pacific Ocean. Nature 412, 635-638.

Conflict of Interest Statement: The authors declare that the research was conducted in the absence of any commercial or financial relationships that could be construed as a potential conflict of interest.

Received: 09 August 2011; paper pending published: 27 August 2011; accepted: 06 October 2011; published online: 25 October 2011.

Citation: Dyhrman ST and Haley ST (2011) Arsenate resistance in the unicellular marine diazotroph Crocosphaera watsonii. Front. Microbio. 2:214. doi: 10.3389/fmicb.2011.00214

This article was submitted to Frontiers in Aquatic Microbiology, a specialty of Frontiers in Microbiology.

Copyright (C) 2011 Dyhrman and Haley. This is an open-access article subject to a non-exclusive license between the authors and Frontiers Media SA, which permits use, distribution and reproduction in other forums, provided the original authors and source are credited and other Frontiers conditions are complied with. 